\title{
Editorial
}

\section{0th International Chemical and Biological Engineering Conference - CHEMPOR 2008 - Integrating Life Sciences \& Engineering Special Section}

This issue contains a special section with selected papers presented at the 10th International Chemical and Biological Engineering Conference - CHEMPOR 2008, held in Braga, Portugal, from the 4th to the 6th of September 2008, www. deb.uminho.pt/chempor2008. The conference was jointly organized by the University of Minho, “Ordem dos Engenheiros", and the IBB - Institute for Biotechnology and Bioengineering, with the support of "Sociedade Portuguesa de Química" and "Sociedade Portuguesa de Biotecnologia".

The CHEMPOR series traditionally brings together both young and established researchers and end users to discuss recent developments in different areas of Chemical Engineering. The scope of this edition was broadened by including Biological Engineering research. "Integration of Life Sciences \& Engineering" and "Sustainable Process-Product Development through Green Chemistry" were two of the leading themes. Papers selected for this special issue represent a good panel for addressing the Integration of Life Sciences \& Engineering.

We wish to thank the authors who have contributed to yield a high scientific standard to this special section. We also extend our gratitude to all reviewers who, through their dedicated efforts, have assisted us in this task.

This special section contains six papers covering the following topics of current interest: (1) roles played by three functional groups (amine, carboxyl and hydroxyl) in the orange waste biomass for sorption of three heavy metals $\left(\mathrm{Cd}^{2+}, \mathrm{Zn}^{2+}\right.$ and $\left.\mathrm{Cr}^{3+}\right)$; (2) optimization of the glycerol-to-ornithine molar ratio in the feed medium for the continuous production of clavulanic acid by Streptomyces clavuligerus; (3) estimation of the mean bubble size in pneumatic reactors based on experimental gas hold-up data and volumetric mass transfer coefficient; (4) integrating realtime optimization and plant-wide control for optimal operation of a continuous bio-ethanol process; (5) scale-up to industrial bioreactors of a control scheme for regulation of the ethanol concentration in fed-batch cultures of $S$. cerevisiae; and (6) the use of Principal Component Analysis and image analysis to monitor high-rate anaerobic granular sludge reactors during load and toxic disturbances.

\author{
Chairman, CHEMPOR 2008 Organizing Committee \\ Eugénio C. Ferreira* \\ Editor, Biochemical Engineering Journal \\ William M. Miller \\ Universidade do Minho, Departamento de \\ Engenharia Biológica, Campus de Gualtar, 4710-057 \\ Braga, Portugal \\ * Corresponding author. Tel.: +351 253604 407; \\ fax: +351253678986. \\ E-mail address: ecferreira@deb.uminho.pt
} (E.C. Ferreira) 